\title{
Uptake of Toxic Silica Particles by Isolated Rat Liver Macrophages (Kupffer Cells) Is Receptor Mediated and Can Be Blocked by Competition
}

\author{
Victoria Kolb-Bachofen \\ Institute for Immunobiology, Medical Faculty, Heinrich-Heine-Universität, D4000 Düsseldorf, Germany
}

\begin{abstract}
Silica particles (quartz dust) are toxic to macrophages after their uptake into these cells. These experiments describe the opsonization mechanism(s) and macrophage receptor(s) involved in silica uptake. Freshly isolated rat liver macrophages (Kupffer cells) were incubated at $37^{\circ} \mathrm{C}$ with silica particles in the presence or absence of autologous or heterologous plasma or purified plasma fibronectin and cell viability was assessed at various times. Within 60 min of coincubation, $>80 \%$ of macrophages were lysed in the presence of plasma or purified fibronectin but not in their absence (viability $>90 \%$ ). Lysis was slower with defibronectinized plasma ( $28 \%$ in $60 \mathrm{~min}$ ). Macrophages could be protected from lysis by addition of the monosaccharide $\boldsymbol{N}$-acetyl-D-galactosamine but not by $\boldsymbol{N}$-acetyl-D-glucosamine. Galactosylated serum albumin but not mannosylated albumin or native albumin exerted full protection from lysis. The pentapeptide GRGDS also prevented macrophage lysis in synergy with $\boldsymbol{N}$-acetyl-galactosamine. Enzymatic deglycosylation of fibronectin reduced lysis significantly. These findings indicate an important opsonizing activity for fibronectin and dual recognition via the lectin-like galactose-specific binding activity of membrane-associated $\mathrm{C}$-reactive protein and by integrin receptor $(\mathrm{s})$. Binding experiments $\left(\right.$ at $4^{\circ} \mathrm{C}$ ) revealed initial binding as primarily galactose-inhibitable, suggesting integrinmediated binding as a later event necessary for effective uptake. (J. Clin. Invest. 1992.90:1819-1824.) Key words: macrophages • rat • fibronectin • C-reactive protein • integrin • silica particles.
\end{abstract}

\section{Introduction}

Quartz dust particles are known to exert rapid and selective killing of macrophages (1) after their uptake into the phagocytes. Killing is dependent on uptake of the particles and leads to destruction of phagolysosomes as the earliest event $(2,3)$. Upon inhalation, silica dust is known to cause persistent inflammation, fibrosis, and granuloma in lung of humans and experimental animals $(4,5)$.

Upon injection into circulation, silica particles have been shown to effectively block various functions of the reticuloendothelial system (6-8), which are exerted mainly by the large

Address correspondence to Prof. Dr. Victoria Kolb-Bachofen, Institute für Immunobiologie, Med. Einrichtungen der Heinrich-Heine-Universität, Moorenstrasse 5, D4000 Dusseldorf, Federal Republic of Germany.

Received for publication 4 November 1991 and in revised form 15 May 1992

\section{J. Clin. Invest.}

(c) The American Society for Clinical Investigation, Inc.

$0021-9738 / 92 / 11 / 1819 / 06 \$ 2.00$

Volume 90, November 1992, 1819-1824 population of resident liver macrophages, the Kupffer cells (9). A number of experimental studies on the role of macrophages in various diseases have used the macrophage-toxic effects of silica to impair in vivo phagocyte function in animals (6, 10, 11).

We now describe experiments where blockade of the toxic action of silica particles, i.e., blockade of their uptake, is used to elucidate the opsonic mechanism(s) and modes of recognition and uptake of silica particles by freshly isolated rat liver macrophages.

\section{Methods}

Chemicals. Silica particles (fraction DQ12) were kindly provided by Dr. Armbruster from the Rheinische Bergbau und Kohle Verein, Dortmund, Germany. The fraction DQ12 consists of medium sized (0.5$3.0 \mu \mathrm{m})$ quartz needles.

Collagenase $\mathrm{H}$ and $\mathrm{N}$-glycanase $\mathrm{F}(\mathrm{N}$-glycosidase $\mathrm{F}$, EC 3.2.2.18 and EC 3.5.1.52) were from Boehringer Mannheim GmBH (Mannheim, Germany), Eagle's Medium from Gibco BRL (Eggenstein, Germany), neoglycoproteins from Janssen Pharmaceutica (Beerse, Belgium), mono- and disaccharides from Fluka AG (Neu-Ulm, Germany). Gelatine-Sepharose 4B was from Pharmacia Fine Chemicals (Heidelberg, Germany). Antisera against the human proteins albumin, immunoglobulins; C-reactive protein (CRP), ${ }^{1}$ serum amyloid protein, complement components C1q, C3, C4, and fibronectin were from Dakopatts (Hamburg, Germany) and Jackson ImmunoResearch Labs, Inc. (West-Grove, PA). All other chemicals were obtained from Sigma Chemical Co. ( Tau f kirchen, Germany).

Isolation of rat liver macrophages. Rat liver macrophages were obtained by isolated liver perfusion with Collagenase $\mathrm{H}(180 \mathrm{mg}$ in 100 $\mathrm{ml}$ perfusion buffer) and differential centrifugation of the resulting cell suspension, exactly as described previously (12). The resulting preparation routinely contained $>80 \%$ macrophages with $\sim 10 \%$ contaminating hepatocytes and endothelial cells each. All experiments were performed with freshly isolated liver macrophages.

Plasma preparation. Blood was drawn from healthy volunteers or from rats without any chelating agent or with EDTA $(10 \mathrm{mM})$. Care was taken to avoid air contact and cells were immediately removed by centrifugation. $0.5 \mathrm{ml}$ of plasma or $0.5 \mathrm{ml}$ of purified plasma fibronectin ( $\sim 200 \mu \mathrm{g} / \mathrm{ml}$, see below) in Tris-buffered saline ([TBS]: $50 \mathrm{mM}$ Tris, $100 \mathrm{mM} \mathrm{NaCl}, \mathrm{pH} 7.2$ ] was incubated with $50 \mu \mathrm{l}$ of silica suspension $(5 \mathrm{mg} / \mathrm{ml} \mathrm{TBS})$ for $30 \mathrm{~min}$ at room temperature. This suspension was then used for macrophage incubations. For controls, $50 \mu \mathrm{l}$ of silica was incubated with TBS in the absence of any protein but otherwise under identical conditions (sham incubation).

Plasma fibronectin ( $p F n$ ) isolation. Fibronectin was isolated exactly as described (13): $20 \mathrm{ml}$ of rat plasma (with $10 \mathrm{mM}$ EDTA) was applied to a Gelatin-Sepharose column (20-ml bed size), washed with TBS buffer ( $20 \mathrm{mM}$ Tris, $100 \mathrm{mM} \mathrm{NaCl}, 0.1 \mathrm{mM}$ PMSF). A second wash with TBS plus $1 \mathrm{M}$ urea was followed by elution of pFn with $4 \mathrm{M}$

1. Abbreviations used in this paper: CRP, C-reactive protein; GalNac, $N$-acetyl-galactosamine; GlcNAc, $N$-acetyl-glucosamine; GRDGS, Gly-Arg-Gly-Asp-Ser; mCRP, membrane-associated CRP; pFn, plasma fibronectin; $\mathrm{pFn}-\mathrm{Au}$, fibronectin-coated colloidal gold particles; TBS, Tris-buffered saline. 
urea in TBS. Purity of each isolation was checked by SDS-PAGE and silver staining, only preparations with no contamination were used. Purified $\mathrm{pFn}$ was used after extensive dialysis against TBS.

Deglycosylation of $p F n$-coated silica. For experiments with deglycosylated fibronectin, enzymatic cleavage of glycans was performed on pFn immobilized (attached) to silica particles as described above. Enzymatic digestion with $N$-glycanase $F$ was performed as recommended by the manufacturer: $100 \mu$ l of purified rat $\mathrm{pFn}$-coated silica was centrifuged $(10,000 \mathrm{~g}, 5 \mathrm{~min}$ ), washed twice with Tris-buffer ( $50 \mathrm{mM}$ Tris, pH 8.0) and resuspended in $50 \mathrm{mM}$ Tris (pH 8.0), $20 \mathrm{mM}$ EDTA, $0.1 \%$ Triton $\mathrm{X}-100$, and $4 \mathrm{U} \mathrm{N}$-glycanase F. After incubating at $37^{\circ} \mathrm{C}$ for $6 \mathrm{~h}$, silica was again washed three times and finally resuspended in TBS. An aliquot of $\mathrm{pFn}$-silica was sham incubated without $N$-glycanase $F$ but otherwise identically. Particle aggregation by serial dilutions of ricin $\left(\mathrm{RCA}_{120}\right)$ and Con $\mathrm{A}$ was used to evaluate the success of deglycosylation as described previously (14), which showed a significant though not complete $(\sim 80 \%)$ reduction in agglutinability.

Cell incubation. $50 \mu \mathrm{l}$ of isolated Kupffer cell suspension $\left(2 \times 10^{6}\right.$ cells $/ \mathrm{ml}$ ) in Eagle's medium was mixed with $25 \mu$ l of plasma-silica mixture or pFn-silica and $\mathrm{CaCl}_{2}$ added to a final concentration of 2 $\mathrm{mM}$. Cells plus silica were incubated at $37^{\circ} \mathrm{C}$ for the times indicated. For cell viability by trypan blue exclusion test aliquots were drawn from cell suspensions, mixed with an equal volume of $0.5 \%(\mathrm{wt} / \mathrm{vol})$ trypan blue solution and immediately counted.

Electron microscopy. Adsorption of purified pFn onto colloidal gold particles with a mean diameter of $17 \mathrm{~nm}(\mathrm{pFn}-\mathrm{Au})$ and cell-binding assays with $\mathrm{pFn}$-Au were performed as described previously (14). Briefly, cells were mixed with pFn-Au in Eagle's medium plus $\mathrm{CaCl}_{2}(2$ $\mathrm{mM}$ ) incubated for $10 \mathrm{~min}$ at $4^{\circ} \mathrm{C}$. Binding was stopped by addition of an equal volume of ice-cold cacodylate-HCl-buffered $0.2 \%$ glutardialdehyde, immediately centrifuged, washed twice to remove unbound particles, and then processed for transmission electron microscopy. Ligand binding was quantified on electron micrographs of ultrathin sectioned specimens at a final magnification of $20,000 \times$. Numbers of gold particles bound to the plasma membrane were counted and the length of plasma membranes determined using an HP 65 (HewlettPackard, Düsseldorf, Germany) equipped with a digitizing board and an area/distance program (HP-menu, Hewlett-Packard).

\section{Results}

Silica-mediated macrophage killing depends on opsonization by $p F n$. Isolated rat liver macrophages incubated at $37^{\circ} \mathrm{C}$ with silica particles in the absence of serum proteins can be maintained for $60 \mathrm{~min}$ and longer without loss of viability (Fig. 1). Addition of autologous plasma, obtained without coagulation inhibitors, leads to time dependent loss of viability as assessed by trypan blue exclusion and will lead to up to $80 \%$ dead cells within $60 \mathrm{~min}$. Decrease of live cells is identical with addition of xenogeneic plasma of human origin (Fig. 1).

Electron microscopy of cells thus incubated confirms that lysis of macrophages was dependent on previous endocytosis of silica particles. Disruption of internal phagolysosomal membranes in the vicinity of silica needles was frequently found (Fig. 2). Micrographs also showed that in the absence of plasma absolutely no uptake was observed (not shown).

Agglutination of human plasma-opsonized silica particles with a series of antisera against human plasma proteins (albumin, immunoglobulins, serum amyloid protein, CRP, complement components $\mathrm{Clq}, \mathrm{C} 3, \mathrm{C} 4$, fibronectin) showed that the particles were coated by fibronectin mostly, with little complement $\mathrm{C} 3$, traces of $\mathrm{Clq}$, and none of the other proteins tested detectable.

To prove the dominant role of fibronectin in opsonization we repeated the macrophage toxicity assay described above by

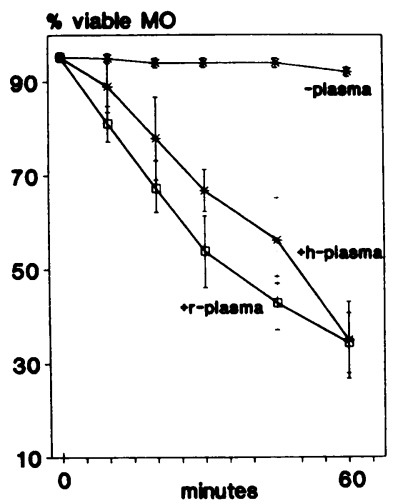

adding purified autologous rat plasma fibronectin. As shown in Fig. 3, results are identical. In confirmation of $\mathrm{pFn}$ as the most important opsonic signal, addition of $\mathrm{pFn}$-free plasma led to a small decrease of macrophage viability only ( statistically signifcant from plasma or purified pFn: $P<0.005)$.

Inhibition with monosaccharides or (neo) glycoproteins. We had previously shown that immobilized fibronectin is bound by liver macrophage membrane-associated CRP ( $\mathrm{mCRP}$ ), earlier termed galactose-particle receptor, in a galactose $/ N$-acetylgalactosamine inhibitable way (14). Therefore incubation experiments with plasma- or pFn-opsonized silica and liver macrophages in the presence of various monosaccharides were performed. Whereas neither $N$-acetyl-glucosamine (GlcNAc) nor mannose addition had any effect on macrophage survival, $N$-acetyl-galactosamine (GlcNAc) blocked uptake of the opsonized particles (Fig. 4). The extent of blockade was the same with rat plasma or human plasma or purified fibronectin as opsonizing agents.

Inhibition experiments were also performed with glycoproteins and neoglycoproteins. As shown in Fig. 5, the two glycoproteins exposing terminal galactosyl groups completely prevented the toxic effect in a concentration-dependent way. Asialofetuin exposing a maximum of 12 terminal galactose residues per molecule exerted half-maximal inhibition at a concentration of $\sim 2 \times 10^{-5} \mathrm{~mol} /$ liter, galactose-BSA containing an average of 37-45 gal per molecule showed half-maximal inhibition at $\sim 5 \times 10^{-8} \mathrm{~mol} /$ liter. Neither mannose-BSA nor native BSA had significant protective effects, proving the galactosespecific recognition mode involved.

The relative inhibitory activity of the glycoproteins was measured with rat plasma, purified rat $\mathrm{pFn}$, or purified human pFn. Comparison of the data obtained showed no difference, neither in the various carbohydrate compounds nor in their relative concentrations needed for inhibition.

Role of Arg-Gly-Asp (RGD)-recognizing integrin receptors. The experiments described confirm a major role of fibronectin as opsonizing signal and a galactose-specific recognition by mCRP. Fibronectin, however, is known to be bound to many cell surfaces, including macrophages, via recognition of the RGD sequence by integrin receptors.

Whether the pentapeptide Gly-Arg-Gly-Asp-Ser (GRGDS) would have a protective effect in macrophage-silica incubation experiments was therefore tested. Surprisingly the pentapeptide also prevents lysis in a concentration dependent way with full protection achieved at $2 \mathrm{mg} / \mathrm{ml}$. Again results were identi- 

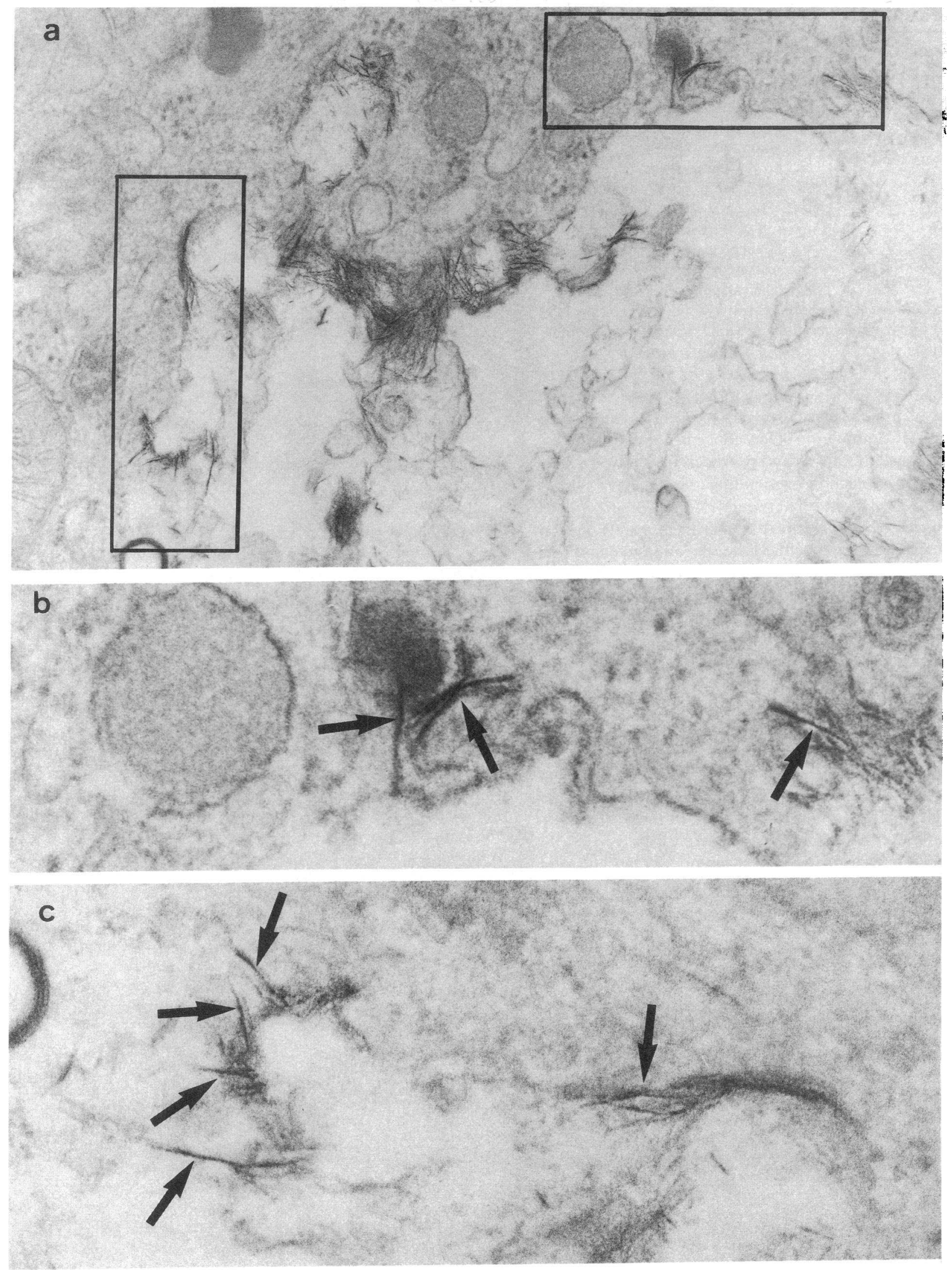

Figure 2. Electron micrographs of freshly isolated liver macrophages incubated with plasma-opsonized silica particles. Liver macrophages were incubated as in Fig. $1\left(+r\right.$-plasma). After incubation for $10 \mathrm{~min}$ at $37^{\circ} \mathrm{C}$, cells were fixed and processed for transmission electron microscopy. Shown are details from a macrophage not yet lysed. (a) Part of a digestive vacuole with ingested silica particles aggregated to bundles. The framed areas are shown at higher magnification in $(b)$ and $(c)$. ( $b$ and $c)$ Silica particles are found outside the vacuoles and rupture of vacuolar lining membrane is evident. 


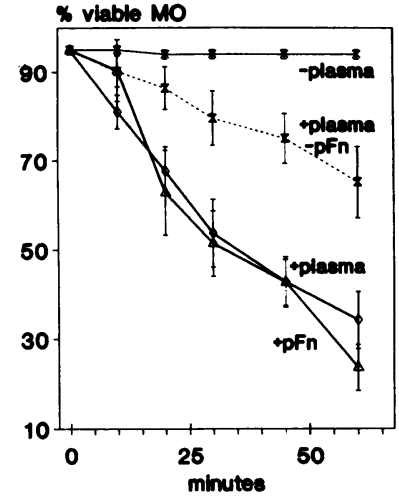

Figure 3. Isolated liver macrophages $(M O)$ were incubated as in Fig. 1. Silica particles were previously incubated either with autologous plasma (+plasma, $\diamond)$, with fibronectin purified from autologous plasma $(+p F n, \Delta)$, with rat plasma after removal of fibronectin by gelatin-Sepharose

(+plasma-pFn, 8$)$ or was sham incubated $(-$ plasma,$\times)$. Comparison of the opsonizing agents show no difference in activity of whole plasma or purified fibronectin whereas removal of fibronectin from plasma diminishes toxic action significantly $(P<0.005$ to plasma at $60 \mathrm{~min}$ ). Values are the mean $\pm \mathrm{SD}$ of three to seven individual experiments.

cal with rat or human plasma or purified $\mathrm{pFn}$ as opsonizing source (Fig. 6). Combination of low concentrations of competing monosaccharide GalNAc and pentapeptide showed synergistic increase in protection from killing (Fig. 7).

Deglycosylation of rat pFn-opsonized silica particles. Silica particles opsonized with purified rat fibronectin were treated with $N$-glycanase $\mathrm{F}$ for $6 \mathrm{~h}$ before cell incubation to determine the role of the glycan portion(s). The enzymatic removal of $\mathrm{N}$-glycans resulted in significant reduction of silica toxicity (Fig. 8) compared with sham-treated particles. The small reduction in cell viability during the 60 -min incubation period could be blocked to control values by addition of GRGDS (Fig. $8 B$ ).

Binding experiments with $\mathrm{pFn}$ adsorbed onto colloidal gold. Since the toxic effect of silica particles depends on their uptake by the cells, binding experiments and quantitative electron microscopy to elucidate the role of the two receptor activities in initial recognition (binding) and/or uptake of opsonized particles were performed. Quartz dust needles contain little electron scattering elements and thus are barely visible as single particles in transmission electron microscopy. The silica visible in Fig. 2 is aggregated to bundles and is thus recognizable. These conditions, however, allow no quantitative measurement of binding. Therefore fibronectin-coated collodidal

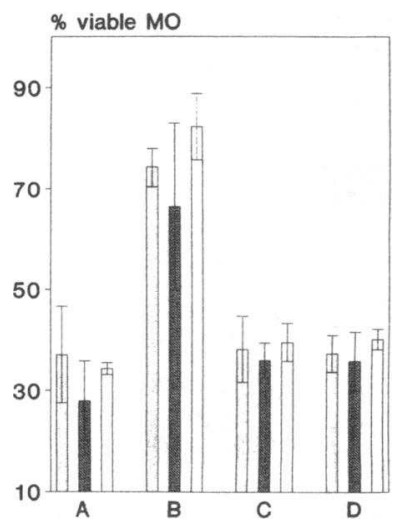

Figure 4. Inhibition of macrophage $(M O)$ lysis by monosaccharides. Liver macrophages were incubated as in Fig. 1 for 60 min at $37^{\circ} \mathrm{C}$ before viability tests. Cells were incubated with: $(A) \mathrm{pFn}$ - or plasma-opsonized silica particles only; $(B)$ as in $(A)$, plus $80 \mathrm{mM}$ $N$-acetyl-D-galactosamine; $(C)$ as in $(A)$, plus $80 \mathrm{mM}$ GlcNAc; $(D)$ as in $(A)$, plus $80 \mathrm{mM}$ mannose. Particles were opsonized either with rat plasma (gray bars) or with rat fibronectin (hatched bars) or with human plasma (open bars). $N$-acetyl-D-galactosamine signifi-

cantly protected cells from toxic action $(P \ll 0.0001$ between values in $B$ and $C$ ). Values are the mean $\pm \mathrm{SD}$ of three to five individual experiments.

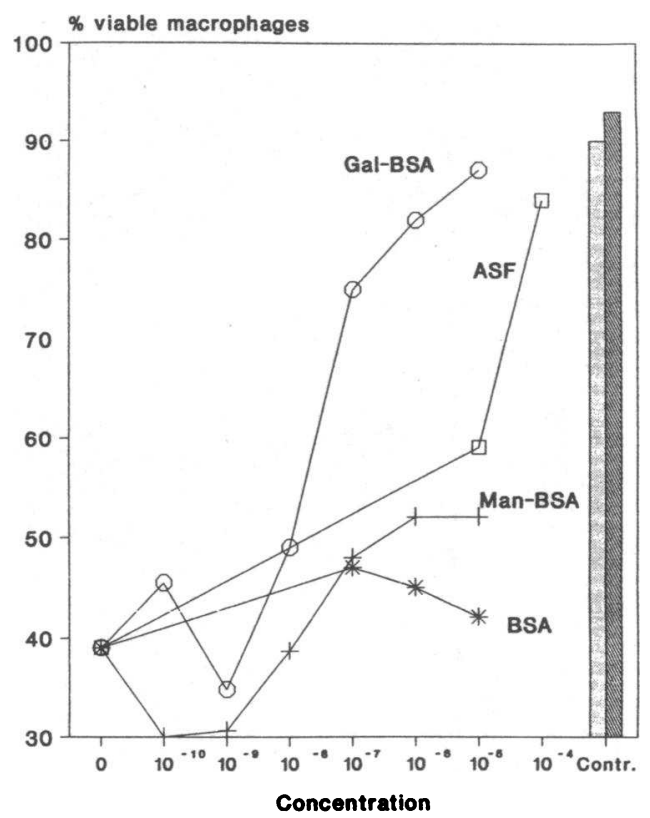

Figure 5. Concentration-dependent inhibition of toxic action by glycoconjugates. Isolated liver macrophages were incubated with rat fibronectin-opsonized silica particles for $60 \mathrm{~min}$ at $37^{\circ} \mathrm{C}$ in the presence of various concentrations of galactosylated bovine serum albumin (Gal-BSA), asialofetuin ( $A S F)$, mannosylated BSA (Man-BSA), or native BSA. Controls were macrophages incubated in the absence of silica (hatched bar) or with unopsonized silica (gray bar).

gold particles ( $\mathrm{pFn}$-Au ) were used in these experiments. Macrophages were incubated with $\mathrm{pFn}$-Au at $4^{\circ} \mathrm{C}$ with or without monosaccharides, pentapeptide, or the mixture. The amount of particles bound per micrometer of plasma membrane was determined on electron micrographs of the fixed and processed specimen. As shown in Fig. 9, binding of pFn-Au was completely inhibited by GalNAc ( significantly different from binding in Fig. $9 A: P<0.001$ ) but not by GlcNAc (no significant difference to Fig. $9 \mathrm{~A}$ ). In contrast, addition of GRGDS at highest concentration $(2 \mathrm{mg} / \mathrm{ml})$ did not lead to complete inhibition of surface binding ( significantly different from GalNAcinhibition: $P<0.001$ ), although uptake at $37^{\circ} \mathrm{C}$ was com-

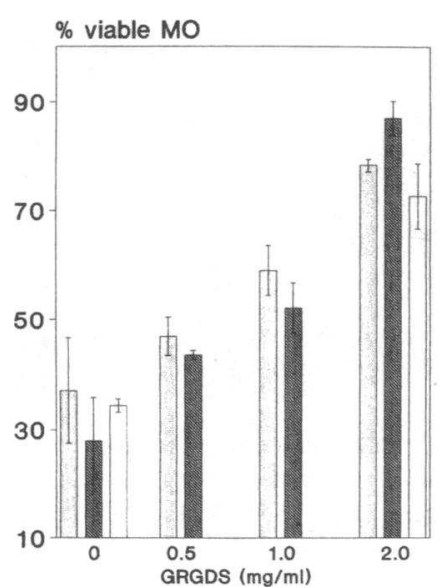

Figure 6. Inhibition of silicamediated toxicity by the pentapeptide GRGDS. Isolated liver macrophages were coincubated with silica particles opsonized with rat plasma (gray bars), with rat fibronectin (hatched bars), or with human plasma (open bars). After $60 \mathrm{~min}$ at $37^{\circ} \mathrm{C}$ in the presence of the pentapeptide GRGDS at concentrations indicated, viability of macrophages $(M O)$ was assessed by trypan blue exclusion. Values at $2.0 \mathrm{mg} / \mathrm{ml}$ GRGDF are significantly different from $0: P \ll 0.0001$. Values are the mean \pm SD of three to four individual experiments. 


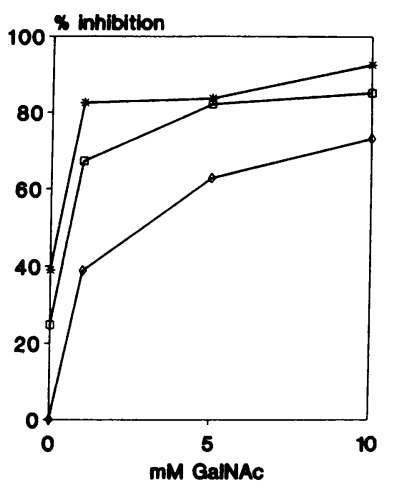

pletely blocked (not shown). The combination of $10 \mathrm{mM} \mathrm{Gal}-$ NAc and $1.0 \mathrm{mg} / \mathrm{ml}$ pentapeptide leads to total inhibition.

\section{Discussion}

Fibronectin is a multifunctional protein (for reviews see references 15-17) supporting, for instance, cell attachment and spreading of eucaryotes, bacterial cell adhesion, binding to a large number of substrates, and triggering a variety of cellular responses, including phagocytosis.

All but one of the functions listed above are now mapped to specific areas of the fibronectin molecule, only the phagocytosis-mediating or -enhancing activity is not yet clearly ascribable to a specific part of the molecule.

The experiments described here strongly support a dominant role for fibronectin as the prime opsonizing signal rendering silica particles recognizable for liver macrophages: comparison of all uptake and inhibition experiments did not show any difference whether whole plasma or purified $\mathrm{pFn}$ was used,
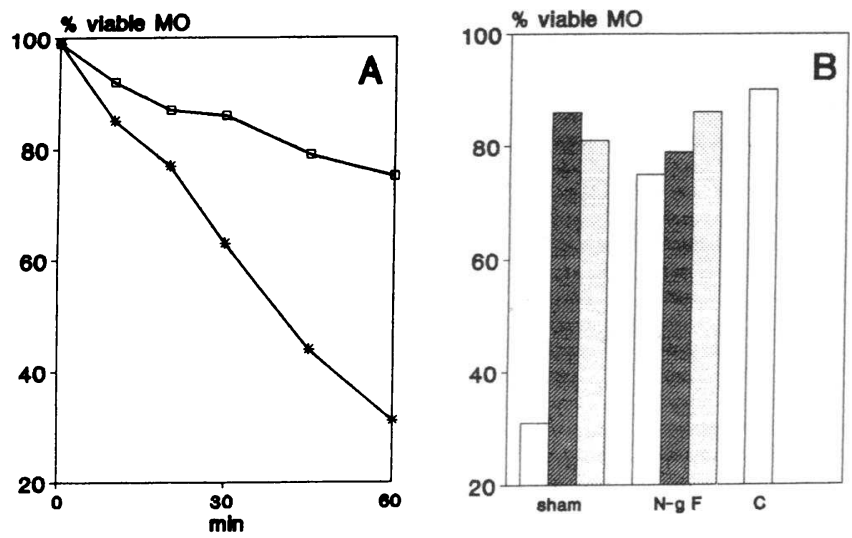

Figure 8 . $\mathrm{N}$-glycanase $\mathrm{F}$ treatment of rat $\mathrm{pFN}$-opsonized silica reduces its macrophage toxicity. Rat pFn-opsonized silica particles were incubated with $N$-glycanase $\mathrm{F}$ or sham incubated as described in Methods before addition to isolated macrophages. $(A)$ Time dependence of silica-mediated macrophage $(M O)$ killing $(\square) \mathrm{N}$-glycanase Ftreated particles, $(*)$ sham-treated particles. $(B)$ Inhibition of killing during an incubation of $60 \mathrm{~min}$ at $37^{\circ} \mathrm{C}$ with sham-treated pFn-silica (sham) or with $N$-glycanase-treated pFn-silica $(N-g-F)$. Control $(C)$ was with sham-incubated silica (as - plasma in Fig. 1). (Open bars) no inhibitor added; (dark bars) in the presence of GalNAc ( $80 \mathrm{mM})$; (gray bars) in the presence of GRGDS ( $2 \mathrm{mg} / \mathrm{ml}$ ).

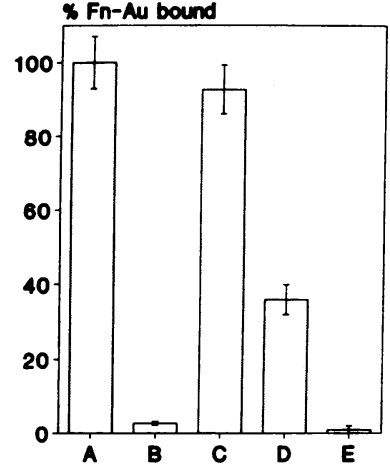

Figure 9. Competitive inhibition of binding of fibronectin-opsonized particles to liver macrophages. Colloidal gold particles were coated with purified rat fibronectin $(F n-A u)$, isolated liver macrophages were coincubated for 10 $\min$ at $4^{\circ} \mathrm{C}$, and cells were processed for transmission electron microscopy. The number of particles bound to cells was measured on electron micrographs. $A$, no additives; $B$, plus GalNAc ( 80 $\mathrm{mM}) ; C$, plus GlcNAc ( $80 \mathrm{mM})$; $D$, plus GRGDS $(2 \mathrm{mg} / \mathrm{ml}) ; E$,

plus GalNAc ( $10 \mathrm{mM})$ and GRGDS $(1 \mathrm{mg} / \mathrm{ml})$. Data are the mean \pm SD from 35 to 45 individual cells micrographed from two different experiments. $100 \%$ binding equals $11.3 \pm 5.8 \mathrm{Fn}$-Au particles/ $10 \mu \mathrm{m}$ plasma membrane.

suggesting that in the presence of $\mathrm{pFn}$ this appears to be the dominant opsonizing molecule. In the presence of $\mathrm{pFn}$-free plasma, silica-mediated macrophage killing is slowed down significantly. This finding is in agreement with the description of high affinity fibronectin receptors on isolated rat liver Kupffer cells (18).

The immobilized fibronectin is recognized by two different receptor activities present on the rat phagocyte and both binding activities have to act in synergy to mediate effective uptake: interference with either one of the two modes of recognition will lead to uptake blockade as visualized by the protective effect for cell viability. This double recognition mode may also explain the relatively high affinity of binding measured for fibronectin-opsonized particles on rat Kupffer cells (18), which was found to be one to two orders of magnitude higher than those measured for RGD recognition by integrins.

A number of very different observations suggest synergism of RGD-recognizing integrins with other binding activities. On T lymphocytes (19) and melanoma cells (20), a second integrin $\left(\alpha_{4} \beta_{1}\right)$ recognizes a peptide sequence (Leu-Asp-Val) in the IIICS domain of the fibronectin molecule. Immobilized but not soluble fibronectin in synergy with anti-CD3 antibodies supports activation and proliferation of naive $\mathrm{T}$ lymphocytes, whereas no effect is found with either of the two factors alone (21). Experimental data on adhesion of microvascular endothelial cells (22) and of fibroblasts (23) on fibronectin-coated surfaces as well as uptake of fibronectin-coated beads by gingival fibroblasts (24) also suggest involvement of additional recognition modes.

The interaction of immobilized but not soluble fibronectin with immobilized CRP has been observed (25-27) and recently we could show that the interaction of a membrane-associated form of CRP ( $\mathrm{mCRP}$ ) on rat liver macrophages (28) with immobilized fibronectin occurs via a low-affinity galactose-specific binding (14).

I therefore now propose that the opsonic activity of the glycoprotein fibronectin partly resides in the peptide sequence of the central cell binding domain of this molecule and partly within its glycan portions, which so far have not been associated with any function besides protection from proteolysis (29).

On the other hand evidence is increasing that low-affinity carbohydrate-specific interactions synergize with attachment 
signals as has been recently shown very elegantly for the low-affinity binding (rolling) via the selectin PADGEM as a prerequisite for the leucocyte adhesion through integrins LFA-1, Mac-1 (30). In direct analogy to these results, I propose that the lowaffinity interaction of $\mathrm{mCRP}$ with fibronectin-coated particles leads to a slowdown of these particles within the circulation, analogous to the leucocyte rolling, as a prerequisite for the development of stable integrin-mediated binding. This proposal is supported by the binding inhibition experiments.

The competition data are of potential interest in prevention of pulmonary diseases associated with toxic and/or excessive dust burden. Both fibronectin as well as CRP are known constituents of broncho-alveolar lavage fluid and were recently described to increase in acute inflammatory processes $(31,32)$. Work is now in progress to examine silica uptake and receptor expression in rat alveolar macrophages.

\section{Acknowledgments}

I thank Andrea Schlömer, Marija Lovrencic, and Ulla Lammersen for excellent technical assistance; Sabine Wenzel-Unger for photographic assistance; and Ingeburg Werner for typing the manuscript.

This work was supported by a grant from the Deutsche Forschungsgemeinschaft (Ko 806/3-1).

\section{References}

1. O'Rourke, E. J., S. B. Halstead, A. C. Allison, and T. A. E. Plattes-Mills. 1978. Specific lethality of silica for human peripheral blood mononuclear phagocytes, in vitro. $J$. Immunol. Methods. 19:137-151.

2. Allison, A. C., J. S. Harington, and M. Birbeck. 1966. An examination of the cytotoxic effects of silica on macrophages. J. Exp. Med. 124:141-154.

3. Heppleston, A. G., and J. A. Styles. 1967. Activity of a macrophage factor in collagen formation by silica. Nature (Lond.). 214:521-522.

4. Davis, G. S. 1986. Pathogenesis of silicosis: current concepts and hypotheses. Lung. 164:139-154.

5. Ziskind, M., R. N. Jones, and H. Weill. 1976. Silicosis. Am. Rev. Respir. Dis. 113:643-665.

6. Zisman, B., E. F. Wheelock, and A. C. Allison. 1971. Role of macrophages and antibody in resistance of mice against yellow fever virus. J. Immunol. 107:236-243.

7. Levy, M. H., and E. F. Wheelock. 1975. Effects of intravenous silica on immune and nonimmune functions of the murine host. J. Immunol. 115:41-48.

8. Chaouat, G., and J. G. Howard. 1976. Influence of reticuloendothelial blockade on the induction of tolerance and immunity by polysaccharides. Immunology. 30:221-227.

9. Saba, T. M. 1970. Physiology and physiopathology of the reticuloendothelial system. Arch. Intern. Med. 129:1031-1052.

10. Brosnan, C. F., M. B. Bornstein, and B. R. Bloom. 1981. The effects of macrophage depletion on the clinical and pathologic expression of experimental allergic encephalomyelitis. J. Immunol. 126:614-620.

11. Oschilewski, M., E. Schwab, U. Kiesel, U. Opitz, K. Stünkel, V. Kolb-Bachofen, and H. Kolb. 1986. Administration of silica or monoclonal antibody to
Thy-1 prevents low-dose streptozotocin-induced diabetes in mice. Immunol. Lett. 12:289-294.

12. Schlepper-Schäfer, J., and V. Kolb-Bachofen. 1988. Red cell aging results in a change of cell surface carbohydrate epitopes allowing for recognition by galactose-specific receptors of rat liver macrophages. Blood Cells. (NY). 14:259269.

13. Engvall, E., and E. Ruoslahti. 1977. Binding of soluble form of fibroblast surface protein fibronectin, to collagen. Int. J. Cancer 20:1-5.

14. Kolb-Bachofen, V., and F. Abel. 1991. Participation of D-galactose-specific receptors on liver macrophages in recognition of fibronectin-opsonized particles. Carbohydr. Res. 214:201-213.

15. Rouslahti, E. 1988. Fibronectin and its receptors. Annu. Rev. Biochem. 57:375-413.

16. Saba, T. M. 1989. Trends in shock research. Fibronectin: relevance to phagocytic host response to injuri. Circ. Shock. 29:257-278.

17. D'Souza, S. E., M. H. Ginsberg, and E. F. Plow. 1991. Arginyl-glycylaspartic acid (RGD): a cell adhesion motif. Trends Biochem. Sci. 16:246-250.

18. Cardarelli, P. M., F. A. Blumenstock, P. J. McKeown-Longo, T. M. Saba, J. E. Mazurkiewicz, and J. A. Dias. 1990. High-affinity binding of fibronectin to cultured Kupffer cells. J. Leukocyte Biol. 48:426-437.

19. Wayner, E. A., A. Garcia-Pardo, M. J. Humphries, J. A. McDonald, and W. G. Carter. 1989. Identification and characterization of the T lymphocyte adhesion receptor for an alternative cell attachment domain (CS-1) in plasma fibronectin. J. Cell Biol. 109:1321-1330.

20. Mould, A. P., A. Komoriya, K. M. Yamada, and M. J. Humphries. 1991. The CS5 peptide is a second site in the IIICS region of fibronection recognized by the integrin $\alpha_{4} \beta_{1}$. J. Biol. Chem. 266:3579-3585.

21. Cardarelli, P. M., S. Yamagata, W. Scholz, M. A. Moscinski, and E. L. Morgan. 1991. Fibronectin augments anti-CD3-mediated IL-2 receptor (CD25) expression on human peripheral blood lymphocytes. Cell. Immunol. 135:105117.

22. Cheng, Y.-F., R. I. Clyman, J. Enenstein, N. Waleh, R. Pytela, and R. H. Kramer. 1991. The integrin complex $\alpha_{\mathrm{v}} \beta_{3}$ participates in the adhesion of microvascular endothelial cells to fibronectin. Exp. Cell Res. 194:69-77.

23. Ylänne, J. 1990. RGD peptides may only temporarily inhibit cell adhesion to fibronectin. FEBS (Fed. Eur. Biochem. Soc.) Lett. 267:43-45.

24. McKeown, M., G. Knowles, and C. A. G. McCulloch. 1990. Role of the cellular attachment domain of fibronectin in the phagocytosis of beads by human gingival fibroblasts in vitro. Cell Tissue Res. 262:523-530.

25. Salonen, E. M., T. Vartio, K. Hedman, and A. Vaheri. 1984. Binding of fibronectin by the acute phase reactant C-reactive protein. J. Biol. Chem. 259:1496-1501.

26. Du Clos, T. W. 1989. C-reactive protein reacts with the U1 small nuclear ribonucleoprotein. J. Immunol. 143:2553-2559.

27. Swanson, S. J., M. M. McPeek, and R. F. Mortensen. 1989. Characteristics of the binding of human C-reactive protein (CRP) to laminin. J. Cell. Biochem. 40:121-132.

28. Kempka, G., P. H. Roos, and V. Kolb-Bachofen. 1990. A membrane-associated form of C-reactive protein is the galactose-specific particle receptor on rat liver macrophages. J. Immunol. 144:1004-1009.

29. Olden, K., R. M. Pratt, and K. M. Yamada. 1978. Role of carbohydrates in protein secretion and turnover: effects of tunicamycin on the major cell surface glycoprotein of chick embryo fibroblasts. Cell. 13:461-473.

30. Lawrence, M. B., and T. A. Springer. 1991. Leukocytes roll on a selectin at physiologic flow rates: distinction from and prerequisite for adhesion through integrins. Cell. 65:859-873.

31. Nagy, B., E. Katona, J. Erdei, L. Karmazsin, and J. Fachet. 1991. Fibronectin in bronchoalveolar lavage fluid and plasma of dogs with acute inflammation of the lungs. APMIS (Acta Pathol. Microbiol. Immunol. Scand.) 99:387-390.

32. Li, J. J., R. L. Sanders, K. P. McAdam, C. A. Hales, B. T. Thompson, J. A Gelfand, and J. F. Burke. 1989. Impact of C-reactive protein (CRP) on surfactant function. J. Trauma. 29:1690-1697. 